\title{
Measuring non-polyaminated lipocalin-2 for cardiometabolic risk assessment
}

\author{
Kangmin Yang ${ }^{1,2}$, Han-Bing Deng ${ }^{1,2+}$, Andy W.C. Man ${ }^{1,2}$, Erfei Song ${ }^{1,2}$, Jialiang Zhang ${ }^{3}$, Cuiting Luo $^{1,2}$, \\ Bernard M.Y. Cheung ${ }^{3}$, Kwok-Yung Yuen ${ }^{4}$, Pia Søndergaard Jensen ${ }^{5}$, Akhmadjon Irmukhamedov ${ }^{6}$, \\ Atlanta G.I.M. Elie ${ }^{7}$, Paul M. Vanhoutte ${ }^{1,2}$, Aimin $\mathrm{Xu}^{1,3}$, Jo G.R. De Mey ${ }^{6,7}$ and Yu Wang ${ }^{1,2 *}$

\begin{abstract}
${ }^{1}$ State Key Laboratory of Pharmaceutical Biotechnology, The University of Hong Kong, Hong Kong, China; ${ }^{2}$ Department of Pharmacology and Pharmacy, The University of Hong Kong, Hong Kong, China; ${ }^{3}$ Department of Medicine, The University of Hong Kong, Hong Kong, China; ${ }^{4}$ Department of Microbiology, The University of Hong Kong, Hong Kong, China; ${ }^{5}$ Department of Clinical Biochemistry and Pharmacology, Odense University Hospital, Odense, Denmark; ${ }^{6}$ Department of Cardiac, Thoracic and Vascular Surgery, Odense University Hospital, Odense, Denmark; ' Department of Cardiovascular and Renal Research, Institute of Molecular Medicine, University of Southern
\end{abstract} \\ Denmark, Odense, Denmark
}

\section{Abstract}

Aims Lipocalin-2 is a pro-inflammatory molecule characterized by a highly diversified pattern of expression and structurefunctional relationships. In vivo, this molecule exists as multiple variants due to post-translational modifications and/or protein-protein interactions. Lipocalin-2 is modified by polyamination, which enhances the clearance of this protein from the circulation and prevents its excessive accumulation in tissues. On the other hand, animal studies suggest that nonpolyaminated lipocalin-2 (npLcn2) plays a causal role in the pathogenesis of obesity-associated medical complications. The present study examined the presence of npLcn2 in samples from healthy volunteers or patients with cardiac abnormalities and evaluated npLcn2 as a biomarker for cardiometabolic risk assessment.

Methods and results Immunoassays were developed to quantify npLcn2 in blood and urine samples collected from 100 volunteers (59 men and 41 women), or venous plasma and pericardial fluid samples obtained from 37 cardiothoracic surgery patients. In healthy volunteers, npLcn2 levels in serum are significantly higher in obese and overweight than in lean subjects. After adjustment for age, gender, smoking, and body mass index (BMI), serum npLcn2 levels are positively correlated with heart rate, circulating triglycerides, high-sensitivity C-reactive protein (hsCRP), and creatinine in plasma. The npLcn2 levels in urine are significantly increased in subjects with metabolic syndrome and positively correlated with BMI, heart rate, circulating triglycerides, and urinary aldosterone. In cardiothoracic surgery patients, the circulating concentrations of npLcn2 are higher (more than two-fold) than those of healthy volunteers and positively correlated with the accumulation of this protein in the pericardial fluid. Heart failure patients exhibit excessive expression and distribution of npLcn2 in mesothelial cells and adipocytes of the parietal pericardium, which are significantly correlated with the elevated plasma levels of npLcn2, total cholesterol, and creatinine.

Conclusions Quantitative and qualitative evaluation of npLcn2 in human biofluid samples and tissue samples can be applied for risk assessment of healthy individuals and disease management of patients with obesity-related cardiometabolic and renal complications.

Keywords Lipocalin-2; Cardio-renal metabolic syndrome; Polyamination; Biomarker

Received: 24 October 2016; Revised: 13 April 2017; Accepted: 4 May 2017

*Correspondence to: Yu Wang, Department of Pharmacology and Pharmacy, The University of Hong Kong, Hong Kong, China. Tel: +852 $39176864 ;$ Fax: +852 2817 0859. Email: yuwanghk@hku.hk

tPresent address. Jockey Club School of Public Health and Primary Care, The Chinese University of Hong Kong, Hong Kong, China.

\section{Introduction}

Lipocalin-2 (also known as neutrophil gelatinase-associated lipocalin, neu-related lipocalin, uterocalin, siderocalin, or
$24 \mathrm{p} 3$ ) is an adipokine circulating in the bloodstream and belongs to the lipocalin family, which functions as transporters of lipophilic substances. ${ }^{1,2}$ Lipocalin-2 possesses unique bacteriostatic properties by sequestering enterobactin ${ }^{3}$ and is 
implicated in cardiometabolic abnormalities associated with obesity, including hypertension, type 2 diabetes, renal injury, and heart failure. ${ }^{4-11}$ Circulating lipocalin-2 levels are augmented in obese human subjects and positively correlated with anthropometric metabolic variables including insulin resistance index, hyperlipidaemia, hyperglycaemia, and inflammation. ${ }^{11}$ Mice without lipocalin-2 are protected against dietary or genetic obesity-induced endothelial dysfunction, hypertension, insulin resistance, and elevation of circulating lipid and glucose levels. ${ }^{4,9,10,12}$ Despite this information, the pathophysiological role of lipocalin-2 remains largely uncharacterized. In particular, there are disputes on the precise type of cells in which the protein is expressed under both physiological and pathological conditions.

Lipocalin-2 is post-translationally modified by polyamination, which promotes the clearance of this protein from the circulation. ${ }^{9}$ In animals fed with high-fat diet, circulating levels of non-polyaminated lipocalin-2 (npLcn2) are significantly increased and contribute to the development of obesity-associated pathologies. ${ }^{9}$ Although pharmacological interventions in mice suggest that treatment with npLcn2 causes vascular inflammation, endothelial dysfunction, and hypertension, there lacks evidence from human studies to support such a pathophysiological role in clinical settings. In the present study, the antibodies and immunoassays specifically recognizing npLcn2 were developed to analyse its expression in different human samples and association with various cardiometabolic risk factors.

\section{Materials and methods}

\section{Human participants}

The study was approved by the Institutional Review Board of the University of Hong Kong/Hospital Authority Hong Kong West Cluster (reference number UW 14-044) and performed in accordance with the International Conference on Harmonisation's Guideline for Good Clinical Practice (ICH GCP) guidelines, local regulations, and Hospital Authority and the University policies to comply with the Declaration of Helsinki. One hundred volunteers including 59 men and 41 women were recruited from Hong Kong community inhabitants from October to December 2015. Informed written consent was obtained from all subjects prior to their participation in the study. Criteria of exclusion were pregnancy or lactation; alcohol intake within the past $24 \mathrm{~h}$; long-term drug treatment or medications taken within 1 week prior to the study; and any known diagnoses of hypertension, diabetes, dyslipidaemia, anaemia, coronary heart disease, chronic obstructive pulmonary disease, asthma, hepatitis, primary hyperaldosteronism, renal dysfunction, and eczema. Anthropometric parameters [including age, body mass index (BMI), waist circumference, heart rate, and systolic and diastolic arterial blood pressures] were assessed by standardized procedures. The healthy volunteer cohort included 37 lean (BMI $\left.<23 \mathrm{~kg} / \mathrm{m}^{2}\right), 27$ overweight $(\mathrm{BMI}=$ $\left.23-24.9 \mathrm{~kg} / \mathrm{m}^{2}\right)$, and 36 obese (BMI $\geq 25 \mathrm{~kg} / \mathrm{m}^{2}$ ) individuals, according to the Asia-Pacific guidelines of obesity classification. ${ }^{13}$ In addition, 37 patients who underwent elective coronary artery bypass grafting (26 subjects), valve replacement surgery (six subjects), or both (five subjects) were recruited at the Odense University Hospital for a study approved by the Medical Ethics Committee of the Region of Southern Denmark (S-20100044). ${ }^{14}$ The demographic and clinical characteristics of all study subjects are summarized in Table 1.

\section{Laboratory analyses}

After overnight (10-12 h) fasting, serum, plasma, and urine samples were collected between 8:00 a.m. and 10:00 a.m. for the Hong Kong participants. Plasma samples were collected from Danish participants the day before surgery. Pericardial fluid and biopsy from the parietal pericardium of the patients were collected during the elective coronary artery bypass grafting or cardiac valve replacement surgeries. Tissue biopsies were fixed in neutral-buffered formalin for $48 \mathrm{~h}$. All biofluid samples were stored at $-80^{\circ} \mathrm{C}$. Fasting blood glucose was analysed using Accu-Chek Advantage II Glucometer (Roche Diagnostics, Mannheim, Germany). Triglycerides, total cholesterol (TC), high density lipoprotein (HDL), and low density lipoprotein (LDL) cholesterol levels in serum samples were analysed using respective LiquiColor test kits from Stanbio Laboratory (Boerne, TX, USA). Circulating lipid and haemoglobin A1c (HbA1c) levels in plasma collected from the Danish patients were measured at the Odense University Hospital. ${ }^{14}$

\section{Immunoassays}

Serum or plasma concentrations of adiponectin, lipocalin-2, high-sensitivity C-reactive protein (hsCRP), and fibroblast growth factor 21 (FGF21) were measured using in-house enzyme-linked immunosorbent assay (ELISA) kits (http://www.pharma.hku.hk/ sweb/antibody/ELISA.php) as described. ${ }^{15-22}$ Plasma and urinary creatinine were measured using a commercial kit according to the manufacturer's instructions (ABCAM, Cambridge, UK). The concentrations of haptoglobin and kidney injury molecule-1 (KIM-1) in urine samples were determined by ELISA kits purchased from Biovendor (Candler, NC, USA) and R\&D Systems (Minneapolis, MN, USA), respectively. Aldosterone levels were determined in serum and urine samples using the DetectX Aldosterone Enzyme Immunoassay kit (Cayman Chemical, Ann Arbor, MI, USA). In brief, steroids were extracted from $60 \mu \mathrm{L}$ of serum with ethyl acetate, dried, and dissolved in $140 \mu \mathrm{L}$ assay buffer, whereas $28 \mu \mathrm{L}$ urine samples were diluted five-fold with assay buffer. For measurement, $100 \mu \mathrm{L}$ of serum 
Table 1 Characteristics of the study subjects ${ }^{a}$

\begin{tabular}{lcc}
\hline Parameters & Hong Kong healthy volunteers & Danish patients \\
\hline Age (years) & $48 \pm 7$ & $69 \pm 9$ \\
Current/former/never smokers & $9 / 9 / 82$ & $5 / 7 / 25$ \\
BMI (kg/m ${ }^{2}$ ) & $23.8 \pm 2.7$ & $28.7 \pm 5.5$ \\
Waist circumference (cm) & $82 \pm 7$ & - \\
Heart rate & $65 \pm 8$ & $135 \pm 21$ \\
SBP $(\mathrm{mmHg})$ & $117 \pm 14$ & $73 \pm 13$ \\
DBP $(\mathrm{mmHg})$ & $74 \pm 11$ & - \\
FBG (mmol/L) & $5.8 \pm 0.7$ & $1.4 \pm 0.6$ \\
Triglycerides (mmol/L) & $1.7 \pm 0.8$ & $3.8 \pm 0.9$ \\
TC (mmol/L) & $5.4 \pm 0.9$ & $1.1 \pm 0.4$ \\
HDL (mmol/L) & $1.6 \pm 0.2$ & $2.1 \pm 0.9$ \\
LDL (mmol/L) & $3.5 \pm 0.9$ & $94.6 \pm 30.1$ \\
Plasma creatinine $(\mu \mathrm{mol} / \mathrm{L})$ & $52.5 \pm 9.6$ & $3.9(1.8-8.4)$ \\
Plasma hsCRP (mg/L) & $2.1(1.0-7.5)$ & $134.2(52.9-225.9)$ \\
Plasma FGF21 (ng/L) & $81.7(30.4-138.6)$ & $78.3 \%$ \\
Anti-hypertensive drugs & - & $56.7 \%$ \\
Statins & - & $29.7 \%$ \\
Anti-diabetic drugs & - & $53 \pm 8 \%$ \\
Left ventricular ejection fraction & - & \\
\hline
\end{tabular}

DBP, diastolic blood pressure; FBG, fasting blood glucose; FGF21, fibroblast growth factor 21.

${ }^{a}$ Data are shown as means \pm SD or median (interquartile range) when not normally distributed.

extracts or urine dilutions was incubated with $50 \mu \mathrm{L}$ solutions containing DetectX aldosterone conjugate and antibodies in coated 96 well plates overnight at $4^{\circ} \mathrm{C}$. After washing with phosphate-buffered saline (PBS) and adding the substrates for $30 \mathrm{~min}$, the reactions were terminated and the absorbance was read at $450 \mathrm{~nm}$ using a plate reader (BioTek Instruments Inc., Winooski, VT, USA).

\section{Antibody production and validation}

Wild-type human lipocalin-2 is polyaminated. ${ }^{9}$ Replacing the cysteine 87 residue by alanine (C87A) in human lipocalin-2 significantly reduces the amount of polyamines bound to the protein. ${ }^{9}$ C87A exhibits a longer plasma half-life than did wildtype human lipocalin-2 and induces vascular inflammation. ${ }^{9}$ Here, wild-type human lipocalin-2 and the C87A mutant were expressed as His-tagged recombinant proteins and purified as described. ${ }^{9,11}$ After the removal of endotoxin, the protein purity was confirmed by sodium dodecyl sulfate polyacrylamide gel electrophoresis (SDS-PAGE) and mass spectrometry analysis. Polyclonal antibodies against human lipocalin-2 or C87A were produced as described. ${ }^{9,11}$ The two types of antibodies exhibited different affinities to purified human lipocalin-2 or C87A protein. The antibody against C87A could barely recognize wild-type human lipocalin-2 during immunoprecipitation (Figure S1). The antibodies were subsequently purified by affinity chromatography for testing in human urine samples. In brief, after removing the sediments by centrifugation at $2000 \mathrm{~g}$ for $5 \mathrm{~min}, 100 \mathrm{~mL}$ urine samples were concentrated to $1 \mathrm{~mL}$ using a centrifugal filter concentrator (Millipore ${ }^{\circledR}$ UFC900308 Amicon ${ }^{\circledR}$ Ultra-15 with 3000 Da nominal molecular weight limit). Fifteen microlitres of the concentrated urine samples was separated by SDS-PAGE, transferred to polyvinylidene difluoride membranes, and incubated with antibodies against either human lipocalin-2 or C87A. The immune-complexes were detected with chemiluminescence reagents from GE Healthcare (Uppsala, Sweden). Both antibodies are able to detect lipocalin2 , however, with different patterns of migration and abundance (Figure S2). For immunoprecipitation, the concentrated urine samples containing $500 \mu \mathrm{g}$ proteins were diluted in $500 \mu \mathrm{L}$ PBS, pre-cleared with $50 \mu \mathrm{L}$ protein A agarose beads slurry (Thermo Fisher Scientific, Waltham, MA, USA), and then incubated overnight with $2.5 \mu \mathrm{g}$ of antibodies against either human lipocalin-2 or C87A at $4^{\circ} \mathrm{C}$ under gentle agitation. Samples were then incubated with $100 \mu \mathrm{L}$ of $50 \%$ protein $\mathrm{A}$ agarose beads slurry at room temperature for $2 \mathrm{~h}$ under rotary agitation. After washing three times with PBS, the immune-complexes were eluted with SDS-PAGE loading buffer for western blotting to detect the amount of polyamines attached to the precipitated lipocalin-2 using a specific antibody against spermidine (ABCAM). Compared with the proteins precipitated by antibodies against wild-type human lipocalin-2, the protein precipitated by the antibodies against C87A contained a barely detectable amount of polyamines (Figure $S 2 B$ ). Thus, the two antibodies recognize polyaminated lipocalin-2 (pLcn2) and npLcn2, respectively.

\section{Development of sandwich ELISA}

The sandwich ELISA for measurement of human lipocalin-2 or pLcn 2 has been reported. ${ }^{11,15,19}$ In addition, a sandwich ELISA for npLcn2 measurement was established using unlabeled and biotinylated C87A antibodies for coating and detection, respectively. Biotinylation was performed with a kit from Thermo Scientific $^{\mathrm{TM}}$ Pierce $^{\mathrm{Tm}}$, and free biotin removed by dialysis. The microtitre plate was pre-coated with $100 \mu \mathrm{L}$ 
unlabeled antibodies $\left(2 \mu \mathrm{g} / \mathrm{mL}\right.$ ) overnight at $4^{\circ} \mathrm{C}$ and then blocked with $100 \mu \mathrm{L}$ of PBS containing $1 \%$ bovine serum albumin (BSA) and 0.05\% Tween-20 for $2 \mathrm{~h}$ at room temperature. For measurement, $100 \mu \mathrm{L}$ diluted (25-fold) serum or non-diluted urine, or recombinant protein standards was applied into each well of the coated ELISA plates for $1 \mathrm{~h}$ incubation at room temperature, followed by three washings and another hour of incubation with biotinylated antibodies. The bound immunocomplexes were detected with streptavidin-conjugated horseradish peroxidase and substrates. The reactions were stopped before measurement of the absorbance at $450 \mathrm{~nm}$ with a plate reader (BioTek Instruments Inc.). The inter-assay and intra-assay coefficients of variance were determined by measuring six plasma samples from healthy subjects in a total of five independent assays with duplicate determinations.

\section{Immunohistochemistry}

Formalin-fixed, paraffin-embedded tissue sections (5 $\mu \mathrm{m}$ of thickness) were preheated at $60^{\circ} \mathrm{C}$, deparaffinized, hydrated, and then subjected for antigen retrieval in $0.01 \mathrm{M}$ citrate buffer $(\mathrm{pH}$ 6.0). The endogenous peroxidase activity was quenched with $0.3 \% \mathrm{H}_{2} \mathrm{O}_{2}$ for $15 \mathrm{~min}$ at room temperature. After blocking with $5 \% \mathrm{BSA}$ in PBS for $30 \mathrm{~min}$ at room temperature, the tissue sections were incubated with antihuman lipocalin-2 (5 $\mu \mathrm{g} / \mathrm{mL}$ in PBS containing $5 \% \mathrm{BSA}$ ) or anti-C87A ( $5 \mu \mathrm{g} / \mathrm{mL}$ in PBS containing $5 \%$ BSA) antibodies overnight at $4^{\circ} \mathrm{C}$. Anti-rabbit secondary antibodies (1:1000, P0448; Dako, Glostrup, Denmark) were applied for $45 \mathrm{~min}$ at room temperature, followed by colorimetric detection with 3.3'-diaminobenzidine. All sections were counterstained with Mayer's haematoxylin prior to analysis under a microscope (BX51; Olympus, Tokyo, Japan) and with the Olympus cellSens Entry imaging software, version 1.7.

\section{Targeted disruption of murine Lcn2 gene}

The flippase recognition target (FRT)-Neo-FRT-loxP (1898 bp) was inserted in intron 1 and the loxP site located downstream of exon 2 of LCN2 (ENSMUSG00000026822, http://www. ensembl.org/index.html). Following selection, positive embryonic stem clones were introduced into C57BL/6 blastocysts to produce chimeric mice, which were cross-bred with C57BL/6J mice. The Lcn2-floxed mice were obtained and subsequently crossed with the LysCre B6.129P2-Lyz2tm1(cre) Ifo/J mice from Jackson Laboratory (Bar Harbor, ME, USA), which expressed a Cre recombinase from the lysozyme M-encoding locus. The myeloid lineage-specific lipocalin-2 knockout mice (Lys-LKO) were produced and maintained on a C57BL/6J background. Three sets of primers were used for genotyping. Primer 1 (forward 5'-AAATGCTTCTGTCCGTTTGC-3' and reverse
5'-CGGCATCAACGTTTCTTT-3') was used for amplifying a 128 bp fragment of the Cre recombinase sequence. Primer 2 (forward 5'-TGAATGAACTGCAGGACGAG-3' and reverse $5^{\prime}$ TGATGCTCTTCGTCCAGATCAT-3') and Primer 3 (forward 5' GAGCGATCAGGTAGGACCCT-3' and reverse 5'-CCTGCCCCGGA ACTGCAAGA-3') were used for amplifying a $319 \mathrm{bp}$ fragment of the floxed LCN2 and a $437 \mathrm{bp}$ fragment of wild-type LCN2, respectively.

\section{Neutrophil-mesothelial cell interactions}

The human mesothelial cell line MeT-5A (ATCC ${ }^{\circledR}$ CRL-9444 $^{\mathrm{TM}}$ ) was purchased from American Type Culture Collection (ATCC, Manassas, VA, USA) and cultured in M199 medium. The human primary mesothelial cells were purchased from ZenBio (Zen-Bio Inc., Research Triangle Park, NC, USA) and cultured in MSO-1 (Zen-Bio Inc.). After $48 \mathrm{~h}$, the conditioned media were collected for neutrophil cell incubation. Neutrophils were harvested from lipocalin-2 general knockout mice. ${ }^{9,10}$ In brief, bone marrow cells were flushed out from femurs and tibias with $\mathrm{Ca}^{2+} / \mathrm{Mg}^{2+}$-free Hank's buffered saline solution supplemented with $20 \mathrm{mM}$ Na-HEPES ( $\mathrm{pH}$ 7.4). The cell suspension was filtered with a $70 \mu \mathrm{m}$ cell strainer (Falcon \#352350) and re-suspended for Percoll density gradient separations. After centrifuging at $1600 \mathrm{~g}$ for $30 \mathrm{~min}$, neutrophils were collected between the layers of $78 \%, 69 \%$, and $52 \%$ Percoll and incubated with the conditioned media for $4 \mathrm{~h}$ at $37^{\circ} \mathrm{C}$ prior to analyses.

\section{Statistical analysis}

All statistical calculations were performed with the IBM (Chicago, IL, USA) SPSS version 21.0 software. Data were expressed as means \pm SD or medians with interquartile range, as appropriate. The Kolmogorov-Smirnov test was used to analyse the distribution of different variables. Natural logarithmic transformation was applied for data with nonnormal distribution. The independent $t$-test was used for comparison of continuous variables between two groups. Partial Pearson correlations were used to establish the relationship between variables of interest, with adjustment for age and gender. A $P$ value of less than 0.05 was used to indicate a significant difference in all statistical comparisons.

\section{Results}

\section{Gender differences}

The levels of pLcn2 and npLcn2 in serum and urine samples collected from the healthy volunteer cohort were analysed using in-house ELISA kits (Table 2). The average concentrations 
of pLcn2 in serum were comparable with those in urine samples, whereas the average concentrations of serum npLcn2 were higher (more than 25-fold) than those of urine npLcn2. Consequently, the ratio $\mathrm{pLcn} 2 / \mathrm{npLcn} 2$ was significantly lower in serum than in urine samples. Both pLcn2 and npLcn2 concentrations were significantly lower in serum samples of female participants than those of male subjects. However, pLcn2 and npLcn2 levels in urine samples from female subjects were higher (about five-fold and about two-fold, respectively) than those from male subjects (Table 2). The gender differences of pLcn2 and npLcn2 in serum and urine samples remained significant after adjustment for BMI, waist circumference, and smoking (data not shown). The pLcn2/npLcn2 ratios were not significantly different between men and women. There were no significant associations between serum or urine concentrations of lipocalin-2 and age, for both pLcn2 ( $P=0.303$ and 0.875 , respectively) and npLcn2 ( $P=0.315$ and 0.555 , respectively). The 75th percentile cut-off for serum and urinary lipocalin-2 levels in the healthy volunteers were 121.4 and $106.0 \mathrm{ng} / \mathrm{mL}$ for pLcn2, and 125.8 and $9.1 \mathrm{ng} / \mathrm{mL}$ for $\mathrm{npLcn} 2$, respectively (Figure S3).

Obese subjects (27 men and 9 women) had significantly higher serum pLcn2 (121.5 vs. $57.8 \mathrm{ng} / \mathrm{mL}$ ) and npLcn2 (124.2 vs. $67.6 \mathrm{ng} / \mathrm{mL}$ ) levels than lean subjects (Figure 1A). The overweight subjects also showed significantly higher serum $\mathrm{npLcn} 2$ levels $(89.6 \mathrm{ng} / \mathrm{mL})$ than did lean subjects. According to the National Cholesterol Education Program criteria, ${ }^{23}$ the subjects were grouped into those with zero, one, two, or three risk factors of metabolic syndrome. Urinary npLcn2 levels were

Table 2 Lipocalin-2 concentrations in samples collected from male and female subjects of Hong Kong healthy volunteer cohort ${ }^{\mathrm{a}}$

\begin{tabular}{lccr}
\hline & Total cohort $(n=100)$ & Male $(n=59)$ & Female $(n=41)$ \\
\hline Age (years) & - & $48.2 \pm 7.5$ & $48.3 \pm 7.2$ \\
BMl (kg/m $)$ & - & $24.7 \pm 2.1^{*}$ & $22.7 \pm 3.0$ \\
Waist circumference $(\mathrm{cm})$ & - & $84.9 \pm 5.4^{*}$ & $77.7 \pm 8.0$ \\
Serum pLcn2 $(\mathrm{ng} / \mathrm{mL})$ & $69.8(42.3-126.4)$ & $85.9(48.0-139.7)^{*}$ & $54.2(33.7-79.1)$ \\
Serum $\mathrm{npLn} 2(\mathrm{ng} / \mathrm{mL})$ & $93.8(63.1-143.3)$ & $102.6(69.6-162.0)^{*}$ & $81.5(54.2-105.1)$ \\
Serum pLcn2/npLcn2 & $0.81(0.6-1.0)$ & $0.86(0.7-1.1)$ & $0.76(0.6-0.9)$ \\
Urine $\mathrm{pLcn} 2(\mathrm{ng} / \mathrm{mL})$ & $60.8(20.7-164.1)$ & $30.6(16.3-78.0)^{*}$ & $161.0(35.4-341.4)$ \\
Urine $\mathrm{npLcn} 2(\mathrm{ng} / \mathrm{mL})$ & $3.7(1.7-8.1)$ & $3.0(1.6-5.0)^{*}$ & $6.5(3.0-13.5)$ \\
Urine pLcn2/npLcn2 & $13.76(10.7-21.4)$ & $13.03(10.6-20.8)$ & $15.5(11.8-22.6)$ \\
\hline
\end{tabular}

BMI, body mass index; pLcn2, polyaminated lipocalin-2; npLcn2, non-polyaminated lipocalin-2.

${ }^{a}$ Data are shown as means \pm SD or median (interquartile range) values.

${ }^{*} P<0.05$ vs. female subjects.

Figure 1 Comparison of lipocalin-2 concentrations in serum and urine samples of Hong Kong healthy volunteer cohort. (A) The polyaminated lipocalin2 (pLcn2; left) and non-polyaminated lipocalin-2 (npLcn2; right) levels of serum (top) or urine (bottom) samples were measured and compared among lean, overweight, and obese subjects as defined by the Asia-Pacific guidelines of obesity classification. ${ }^{13}$ (B) The pLcn2 (left) and npLcn2 (right) levels of serum (top) or urine (bottom) samples were measured and compared among subjects with zero, one, two, and three risk factors of metabolic syndrome. $* P<0.05(n=13-37)$.

A

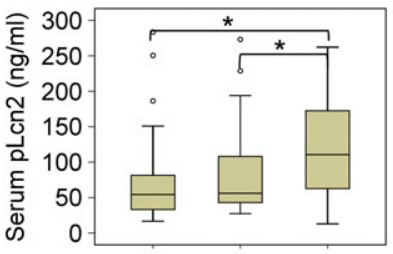

Lean Overweight Obese

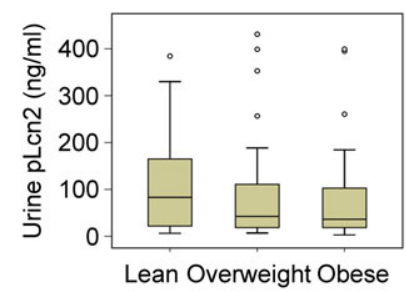

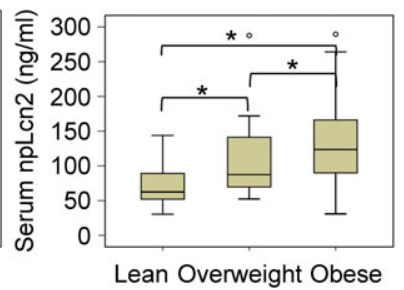

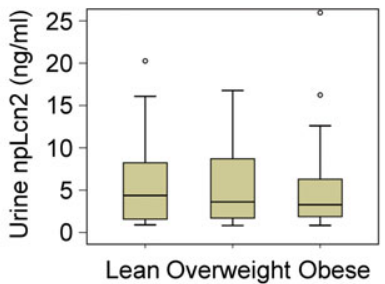

\section{$\mathrm{B}$}
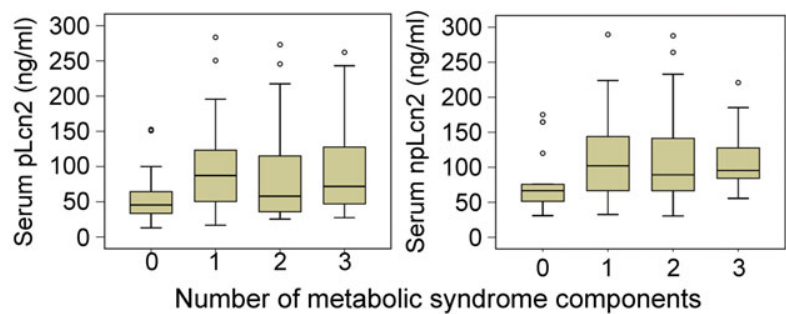

Number of metabolic syndrome components
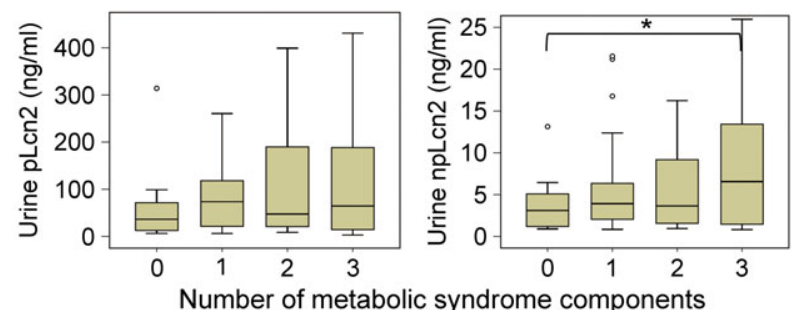
significantly increased in those with three risk factors (13 subjects, five men, and eight women) (Figure 1B).

\section{Correlation analysis for samples from healthy volunteers}

In samples from the healthy volunteer cohort, serum pLcn2 or npLcn2 levels were positively correlated with BMI, heart rate, diastolic blood pressure, triglycerides, plasma hsCRP, and creatinine but negatively correlated with circulating concentrations of adiponectin, independently of age, gender, and smoking (Table 3). After further adjustment for BMI, the positive correlations between $\mathrm{npLcn} 2$ and heart rate, triglycerides, hsCRP, or creatinine remained significant. The serum $\mathrm{pLcn} 2 / \mathrm{npLcn} 2$ ratios were negatively correlated with TC $(r=-0.299, P=0.004)$ or adiponectin $(r=-0.253$, $P=0.015)$, and positively correlated with hsCRP ( $r=0.338$, $P=0.001)$, independently of age, gender, smoking, and BMI.

The concentrations of pLcn2 $(P=0.960)$ or npLcn2 $(P=0.312)$ in the urine were not significantly correlated with those in serum samples. After adjustment for age, gender, and smoking, urinary npLcn2 levels were positively correlated with $\mathrm{BMI}$, heart rate, and serum triglyceride concentrations (Table 4). The correlations between urinary lipocalin-2 levels and serum triglycerides remained significant after further

Table 3 Correlations between serum lipocalin-2 concentrations and study variables of Hong Kong healthy volunteer cohort

\begin{tabular}{|c|c|c|c|c|c|c|c|c|}
\hline & & Seru & $\mathrm{cn} 2^{a}$ & & & Seru & $\mathrm{cn} 2^{\mathrm{a}}$ & \\
\hline & $r^{b}$ & $r^{c}$ & $P^{\mathrm{b}}$ & $P^{c}$ & $r^{b}$ & $r^{c}$ & $P^{\mathrm{b}}$ & $P^{c}$ \\
\hline BMI & 0.362 & - & $<0.001$ & - & 0.376 & - & $<0.001$ & - \\
\hline Waist circumference & - & - & - & - & 0.236 & - & 0.020 & - \\
\hline Heart rate & 0.248 & - & 0.016 & - & 0.287 & 0.214 & 0.004 & 0.036 \\
\hline SBP & - & - & - & - & - & - & - & - \\
\hline DBP & 0.201 & - & 0.052 & - & 0.240 & - & 0.018 & - \\
\hline FBG & - & - & - & - & - & - & - & - \\
\hline Triglycerides & 0.289 & 0.211 & 0.005 & 0.042 & 0.354 & 0.283 & $<0.001$ & 0.005 \\
\hline TC & - & - & - & - & - & - & - & - \\
\hline $\mathrm{HDL}$ & - & - & - & - & - & - & - & - \\
\hline LDL & - & - & - & - & - & - & - & - \\
\hline FGF21 & - & - & - & - & - & - & - & - \\
\hline hsCRP & 0.418 & 0.302 & 0.000 & 0.003 & 0.372 & 0.250 & 0.000 & 0.024 \\
\hline Plasma creatinine & 0.221 & - & 0.029 & - & 0.269 & 0.244 & 0.008 & 0.017 \\
\hline Adiponectin ${ }^{a}$ & -0.330 & 0.222 & 0.001 & 0.034 & -0.297 & - & 0.003 & - \\
\hline
\end{tabular}

BMI, body mass index; DBP, diastolic blood pressure; FBG, fasting blood glucose; FGF21, fibroblast growth factor 21; hsCRP, highsensitivity C-reactive protein; npLcn2, non-polyaminated lipocalin-2; pLcn2, polyaminated lipocalin-2; TC, total cholesterol.

aLogarithmic transformed before analysis.

${ }^{\mathrm{b}}$ Adjusted for age, gender, and smoking.

${ }^{\mathrm{C}}$ Adjusted for age, gender, smoking, and BMI.

Table 4 Correlations between urinary lipocalin-2 concentrations and study variables of Hong Kong healthy volunteer cohort

\begin{tabular}{|c|c|c|c|c|c|c|c|c|}
\hline & \multicolumn{4}{|c|}{ Urine pLen2 } & \multicolumn{4}{|c|}{ Urine npLcn2 } \\
\hline & $r^{a}$ & $r^{\mathrm{b}}$ & $P^{a}$ & $P^{\mathrm{b}}$ & $r^{a}$ & $r^{b}$ & $P^{a}$ & $P^{\mathrm{b}}$ \\
\hline $\mathrm{BMI}$ & - & - & - & - & 0.214 & - & 0.018 & - \\
\hline Waist circumference & 0.202 & 0.191 & 0.029 & 0.037 & - & - & - & - \\
\hline Heart rate & - & - & - & - & 0.167 & - & 0.051 & - \\
\hline SBP & - & - & - & - & - & - & - & - \\
\hline DBP & 0.175 & - & 0.050 & - & - & - & - & - \\
\hline FBG & - & - & - & - & - & - & - & - \\
\hline Triglycerides & 0.214 & 0.199 & 0.021 & 0.031 & 0.228 & 0.184 & 0.012 & 0.043 \\
\hline $\mathrm{TC}$ & - & - & - & - & - & - & - & - \\
\hline $\mathrm{HDL}$ & - & - & - & - & - & - & - & - \\
\hline LDL & - & - & - & - & - & - & - & - \\
\hline Serum aldosterone & - & - & - & - & - & - & - & - \\
\hline Urine aldosterone $^{c}$ & 0.258 & 0.248 & 0.008 & 0.011 & 0.185 & 0.326 & 0.001 & 0.044 \\
\hline Urine KIM-1 [0.15 $(0.02-0.47) \mathrm{ng} / \mathrm{mL}]$ & - & 0.317 & - & 0.001 & - & 0.186 & - & 0.034 \\
\hline Urine haptoglobin $[6.3(6.2-17.9) \mathrm{ng} / \mathrm{mL}]$ & - & - & - & - & - & - & - & - \\
\hline Urine creatinine $[5.0(2.5-12.2) \mathrm{mmol} / \mathrm{L}]$ & - & - & - & - & - & - & - & - \\
\hline
\end{tabular}

BMI, body mass index; DBP, diastolic blood pressure; FBG, fasting blood glucose; KIM-1, kidney injury molecule-1; npLcn2, nonpolyaminated lipocalin-2; pLcn2, polyaminated lipocalin-2; TC, total cholesterol.

${ }^{a}$ Adjusted for age, gender, and smoking.

${ }^{\mathrm{b}}$ Adjusted for age, gender, smoking, and BMI.

'Logarithmic transformed before analysis. 
adjustment for BMI. Both pLcn2 and npLcn2 in urine were significantly correlated with KIM-1, a specific marker for kidney injury. ${ }^{24}$ Urine samples contained a higher level [1009.9 (482.5-2013.6) $\mathrm{pg} / \mathrm{mL}$ ] of aldosterone than did serum samples [106.0 (77.7-131.3) $\mathrm{pg} / \mathrm{mL}$ ]. Aldosterone levels in the urine were positively correlated with waist circumference $(r=0.275, P=0.023)$. The urinary pLcn2 $(r=0.248, P=0.011)$ and npLcn2 $(r=0.185, P=0.044)$ levels were positively correlated with the concentrations of aldosterone in the urine, independently of age, gender, smoking, and BMI (Table 4).

\section{Correlation analysis for samples from cardiothoracic surgery patients}

Among the 37 patients in the Danish cohort (31 male and six female subjects), most had been prescribed cholesterol-lowering, renin-angiotensin system inhibitory, anti-hypertensive, and anti-diabetic medications. ${ }^{14}$ When compared with those of the Hong Kong healthy volunteers, the plasma $\mathrm{pLcn} 2 / \mathrm{npLcn} 2$ ratios were reduced more than four-fold, owing mainly to the increased npLcn2 levels (Table 5). Both pLcn2 and npLcn2 were present in the pericardial fluid samples of all patients, with a median ratio of 0.47 for $\mathrm{pLcn} 2 / \mathrm{npLcn} 2$. The pLcn2 and npLcn2 levels in the pericardial fluid samples correlated significantly with those in the circulation (Table 5). Compared with those with left ventricular ejection fraction (LVEF) over $50 \%$, patients with LVEF equal or below $50 \%$ showed a significant elevation of npLcn2 in both plasma and pericardial fluid samples (Table 6).

Based on National Cholesterol Education Program criteria, $^{23}$ eight patients of the Danish cohort with two or more components of metabolic syndrome had significantly higher concentrations of npLcn2 levels, in both the plasma $(241.9 \pm 54.2 \mathrm{ng} / \mathrm{mL})$ and pericardial fluid samples $(56.3 \pm 25.4 \mathrm{ng} / \mathrm{mL})$, than the 15 subjects exhibiting none of these components $(180.8 \pm 35.6$ and $37.0 \pm 9.6 \mathrm{ng} / \mathrm{mL}$ for plasma and pericardial fluid, respectively); the npLcn2 levels in other patients $(n=14)$ were $213.0 \pm 51.6$ and $49.5 \pm 21.6 \mathrm{ng} / \mathrm{mL}$, respectively (Figure 2). Positive associations were found between plasma levels of npLcn2 and hsCRP $(r=0.359, P=0.017)$ or FGF21 ( $r=0.382$, $P=0.017)$. There were significant positive correlations of plasma creatinine levels with pLcn2 $(r=0.404, P=0.023)$ or npLcn2 ( $r=0.630, P \leq 0.001)$ in pericardial fluid samples.

The presence and distribution of pLcn2 and npLcn2 were analysed by immunohistochemical staining of the pericardial tissue biopsies (Figure S4). While both pLcn2 and npLcn2 were detected in cells (referred to as leucocytes) located within or close to blood or lymph vessels, their patterns of distribution were significantly different when comparing the staining images from adjacent sections. The number of leucocytes containing pLcn2 was significantly less than that 
Table 6 Comparison of lipocalin-2 levels in plasma and pericardial fluid samples of Danish patients according to cardiac function as indicated by left ventricular ejection fraction ${ }^{a}$

\begin{tabular}{lccc}
\hline & \multicolumn{1}{c}{$\begin{array}{l}\text { LVEF }>50 \% \\
(n=27)\end{array}$} & $\begin{array}{c}\text { LVEF } \leq 50 \% \\
(n=10)\end{array}$ & $P$ \\
\hline Plasma pLcn2 & $32.2(24.4-40.4)$ & $48.8(33.3-67.4)$ & 0.090 \\
Plasma npLcn2 & $176.1(138.9-219.2)$ & $214.1(181.6-280.9)$ & 0.038 \\
Fluid pLcn2 & $16.7(13.5-24.0)$ & $25.1(14.2-39.8)$ & 0.138 \\
Fluid npLcn2 & $36.2(26.9-38.8)$ & $56.3(31.3-68.7)$ & 0.029 \\
\hline
\end{tabular}

LVEF, left ventricular ejection fraction; npLcn2, non-polyaminated lipocalin-2; pLcn2, polyaminated lipocalin-2.

${ }^{a}$ Data are shown as median (interquartile range) values.

with npLcn2. Moreover, no positive staining for pLcn2 was found in cells of the paracardial adipose tissue and the mesothelial cell layer.

Based on the distribution of npLcn2 protein, samples were sorted into those with no or less than five positively stained cells (Group I, $n=9$ ), or more than five positively stained cells (mainly leucocytes) (Group II, $n=11$ ), and those with the positive staining widely distributed in leucocytes, adipocytes, and mesothelial cells (Group III, $n=12$ ). Compared with those in Groups I and II, patients in Group III exhibited the highest npLcn2 levels in both plasma and pericardial fluid samples. Among the 10 subjects with LVEF equal or below 50\%, seven were from Group III and showed massive expression and distribution of npLen2 in the pericardium. Compared with
Group I, plasma TC and creatinine concentrations were significantly elevated in patients from both Groups II and III (Figure 3). From Group I to Group III, the plasma HDL and adiponectin levels progressively decreased, whereas the F3 circulating LDL and $\mathrm{HbA} 1 \mathrm{c}$ levels gradually increased (Figure S5). The pericardial fluid contents of hsCRP were the highest in samples from Group III (1.7 $\mathrm{mg} / \mathrm{mL})$ when compared with those in patients of the other two groups $(0.9$ and $1.1 \mathrm{mg} / \mathrm{mL}$ in Groups I and II, respectively).

\section{Protein uptake of lipocalin-2 by neutrophils}

As shown in Figure 3, npLcn2 staining was not found in the mesothelial cells or adipocytes of the pericardium in patient samples of Groups I and II but mainly present in cells within blood or lymphatic vessels. When patients exhibited two or more components of the metabolic syndrome, npLcn2 was detected in leucocytes of samples derived from both Groups II and III. In addition, the latter group displayed excessive expression and accumulation of $n p L c n 2$ in the mesothelial cells and adipocytes of the pericardium (Figure 3 and Figure S5). The results indicated a scavenger role of certain leucocytes in eliminating the locally produced $n p L c n 2$.

To test the above hypothesis, cellular experiment was performed to investigate the interactions between mesothelial

Figure 2 Comparison of lipocalin-2 concentrations in plasma and pericardial fluid samples from Danish patients stratified by the number of the components of metabolic syndrome. Both polyaminated lipocalin-2 (pLcn2; left) and non-polyaminated lipocalin-2 (npLcn2; right) levels were measured and compared for the plasma (top) and pericardial fluid (bottom) samples of Danish patients. ${ }^{*} p<0.05$ vs. the group with zero component of metabolic syndrome $(n=8-15)$.
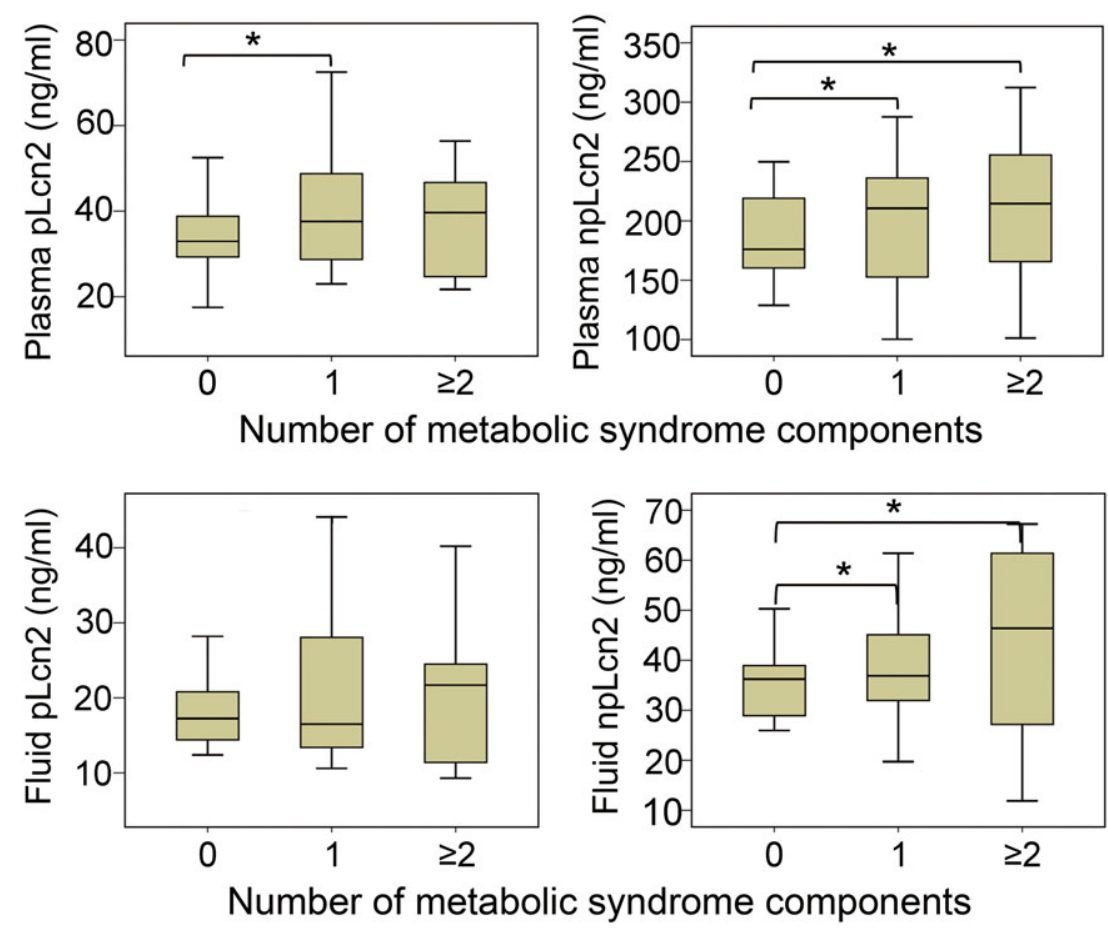
Figure 3 Expression and distribution of non-polyaminated lipocalin-2 (npLcn2) protein in the pericardium tissue biopsies collected from Danish patients during cardiothoracic surgery. (A) Immunohistochemical staining was performed for pericardium tissue sections using polyclonal antibodies against npLcn2. (B) Samples were stratified by the pattern of npLcn2 expression and distribution in pericardium tissue sections. Note that the average left ventricular ejection fraction (LVEF) of patients in Group III was significantly lower than that of Groups I and II. Arrows indicate the positive staining of npLn2. $A=$ adipocytes, $M=$ mesothelial cells, and $L=$ leucocytes. Magnification, $\times 200$. (C) Based on the number of positively stained cells and the distribution pattern, samples were separated into three groups for comparison of their lipocalin-2, total cholesterol, and plasma creatinine levels. $* p<0.05(n=9-12)$.

A
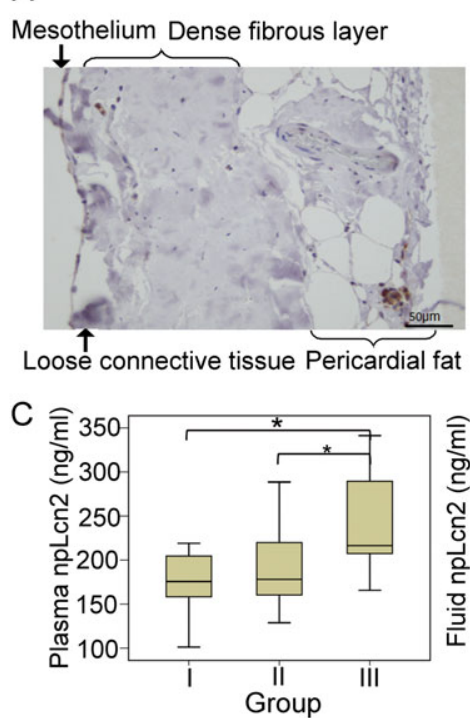

B

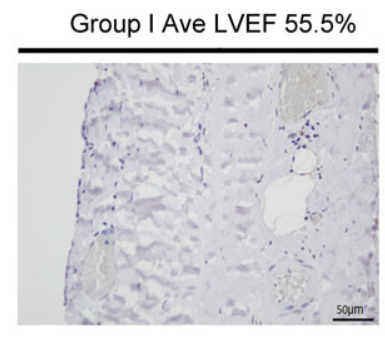

Group II Ave LVEF 55.5\%

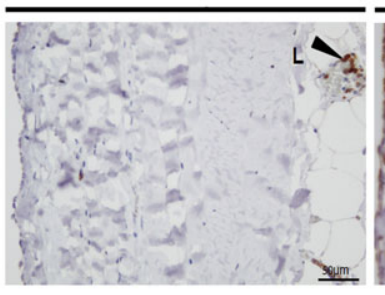

Group III Ave LVEF 50.3\%

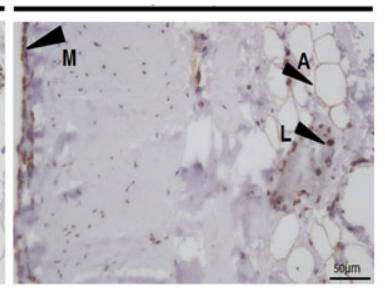

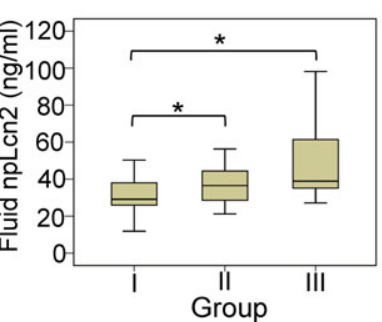
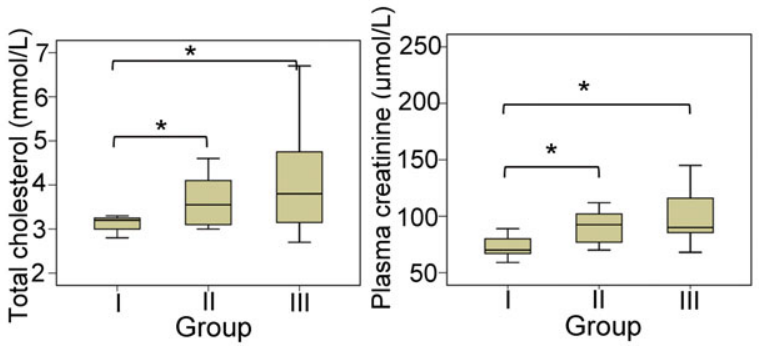

cells and neutrophils. Human lipocalin-2 protein was present in the mesothelial Met-5A cells (Figure S6A). When cultured in the control media, no positive signals for lipocalin-2 were detected in neutrophils isolated from the bone marrow of mice without lipocalin-2. However, positive staining of lipocalin-2 was detected in $\sim 20 \%$ neutrophils cultured in the conditioned media from human primary mesothelial cells (Figure S6B). To further confirm that neutrophils were able to take up exogenous lipocalin-2, mice with selective depletion of LCN2 gene in the myeloid lineage (Lys-LKO) were established (Figure S6C). The mRNA expression of LCN2 was absent in neutrophils isolated from Lys-LKO. However, the protein presence of lipocalin-2 was readily detectable in neutrophils isolated from both Lys-LKO and the control Lcn2-floxed mice (Figure S6D).

\section{Discussion}

Human and murine lipocalin-2 are modified by polyamination. ${ }^{9}$ The amount of polyamines attached to lipocalin-2 determines its circulating half-life and biological activity. Using antibodies specifically recognizing pLcn2 and npLcn2, respectively, the present study demonstrated that endogenous lipocalin-2 exists as both the polyaminated and non-polyaminated forms in human samples including serum, plasma, urine, pericardial fluid, and the parietal pericardium. Compared with those of pLcn2, the expression and distribution of npLen 2 are more sensitively correlated with the risk factors for cardio-renal metabolic syndrome and highly up-regulated in the parietal pericardium of patients with heart failure. The study provided the first evidence to support the existence of npLcn2 in human biofluid and tissue samples. Compared with pLcn2, npLcn2 exhibited different patterns of expression and distribution and was more sensitively correlated with various anthropometric and clinical parameters of cardiometabolic renal syndrome. The levels of $n p L c n 2$ and the ratio of $n p L c n 2$ vs. pLcn 2 could be applied to stratify obese subjects with or without metabolic syndrome, or human patients having or not a severe condition of heart/renal failure. The study also supported npLcn2 as a promising drug target for therapeutic development in obesity-associated medical complications.

Under physiological conditions, lipocalin-2 is undetectable or present at very low levels in the heart and kidney. In response to injury, infection, or other pathological conditions, increased lipocalin-2 expression is found in kidney, heart, liver, colon, and breast tissues. ${ }^{25}$ The rapid rise of urinary lipocalin-2 is an early biomarker for acute renal failure, which occurs in up to $40 \%$ of adults after cardiac surgery and complicates up to $10 \%$ of cardiac surgical procedures in infants and children with congenital heart disease. ${ }^{26,27}$ Only a few studies have reported reference ranges of circulating and urinary 
lipocalin-2 levels in normal subjects. ${ }^{27-29}$ To the best of the authors' knowledge, the present study is the first to report urinary lipocalin-2 levels in a healthy cohort of subjects and a non-hospitalized Chinese population. Urinary npLcn2 levels are significantly augmented in subjects with metabolic syndrome. The results also demonstrate a significantly increased urinary lipocalin-2 but decreased circulating lipocalin-2 in female subjects, when compared with male subjects. It is not known whether or not the source of lipocalin-2 production contributes to the gender differences.

Circulating lipocalin-2 is filtered in the kidney by the glomeruli, while the protein is captured by the proximal tubular epithelial cells. ${ }^{30,31}$ Thus, when injected into the circulation, exogenous lipocalin-2 is enriched in the proximal tubule but does not appear in the urine in large quantities. ${ }^{26}$ This is in line with the present findings that serum and urinary lipocalin-2 levels are not significantly correlated with each other in healthy human subjects. Lipocalin-2 in urine represents a collection of different pools of the protein, including those freely filtered into the tubular space, released from injured tubular cells, and locally expressed and excreted. ${ }^{32,33}$ In response to ischemic or nephrotoxic injury, lipocalin-2 mRNA is expressed in the loop of Henle and the collecting ducts. $^{34}$ This locally synthesized lipocalin-2 is unlikely to be introduced back into the circulation but rather excreted into the urine. ${ }^{35}$ The plasma lipocalin-2 concentration increases progressively with the reduction of glomerular filtration rate (GFR). ${ }^{27}$ Owing to impaired removal of lipocalin-2 from the circulation, urinary lipocalin-2 may represent mainly protein that is expressed/produced locally. ${ }^{36}$ Thus, measurements of lipocalin-2 from different sources have important clinical implications regarding disease progression and treatment strategies. It would be interesting to test whether or not npLcn 2 in urine is produced mainly by the injured tubular/ductal cells, whereas pLcn2 is derived from the circulation via glomerular filtration, or vice versa.

Lipocalin-2 represents an important link between renal and cardiovascular dysfunctions. ${ }^{37,38}$ It is a stronger predictor for mortality than GFR and cystatin C in patients with heart failure. ${ }^{39-41}$ Urinary lipocalin-2 in patients without kidney injury decreases rapidly after cardiac surgery. ${ }^{42}$ Both urinary and plasma lipocalin-2 levels are increased in patients with cardiorenal syndrome types 1 and 2.,43-46 These data collectively suggest that high lipocalin-2 levels do not merely reflect impaired renal function but may be related to the cardiac abnormality per se. In fact, urinary and plasma lipocalin-2 levels are positively associated with increased $\mathrm{N}$-terminal pro-brain natriuretic peptide, the New York Heart Association class, and the left ventricular internal end-diastolic dimension in patients with chronic heart failure. ${ }^{36,47}$ Plasma lipocalin-2 levels correlate with heart failure severity and predict major adverse cardiovascular events in critically ill patients. ${ }^{48}$ The present study demonstrates that npLcn2 represents a more specific marker for cardio-renal metabolic syndrome. In healthy subjects, plasma npLcn2 levels are positively correlated with heart rate, independent of age, gender, smoking, and BMI. In cardiothoracic surgery patients, plasma and pericardial fluid npLcn2 are elevated to a much higher level than pLcn2 and positively correlated with the risk biomarkers such as hsCRP. Importantly, npLcn2 is overexpressed in the pericardium of patients with reduced LVEF, an indicator of heart failure. This group (III) of patients have higher plasma levels of LDL, TC, $\mathrm{HbA} 1 \mathrm{c}$, and creatinine and lower plasma levels of HDL and adiponectin than Groups I and II.

The pericardium is a fibrous-serosal cavity surrounding the heart that contains a small amount of fluid. A monolayer of flattened, squamous-like mesothelial cells lines the inner surface of the pericardial cavity and plays a role in absorbing the pericardial fluid for drainage through the lymphatic capillary bed. In addition to anatomic isolation and lubrication of the moving surfaces of the heart, the normal pericardium prevents cardiac hypertrophy in pressure overload conditions and preserves the negative endothoracic pressure for atrial filling. ${ }^{49}$ A significant amount of npLcn2 is present in the pericardial fluid of patients with heart failure. Histological studies confirmed the expression of npLcn2 protein in the mesothelial cells and the paracardial adipocytes of these patients' biopsies. In addition, about two-thirds of the tissue sections contained npLcn2-positive blood cells (leucocytes), which are mainly located within venules or lymphatic vessels but not arterioles. Although pLcn2 and npLcn2 were both detectable in the leucocytes, their patterns of distribution differed significantly as judged from the staining of adjacent tissue sections. The findings suggest that leucocytes such as neutrophils or macrophages act as scavengers to clear npLcn2 protein from the pericardium. During this process, $n p L c n 2$ is polyaminated inside the leucocytes and stored in the form of pLcn2 for subsequent drainage and elimination. Thus, excessive production and accumulation of $\mathrm{npLcn} 2$ in the pericardium not only determine systemic lipocalin-2 levels but also play a pathogenic role in the development of cardiac diseases. Measurement of different forms of lipocalin-2, especially npLcn2, could be clinically important for early detection, risk stratification, and outcome prediction of patients with cardiorenal abnormalities.

The present study has some limitations, including a relatively low subject number, different pathophysiological mechanisms, lack of longitudinal assessment, absence of information concerning leucocyte counts or renal function in the studied patients, and its observational nature. As a retrospective single-centre analysis, selection bias may not be excluded entirely. Additional research is needed in larger and more diverse patient populations to further evaluate and validate the present findings. Despite these limitations, the present findings suggest that npLcn2 is a novel and sensitive biomarker for cardiometabolic risk and cardio-renal function assessment. Assays used in the present study are 
able to differentiate the pathophysiological expression of pLcn2 and npLen2 in human samples.

\section{Conflict of interest}

None.

\section{Funding}

Seeding Funds for Basic Research of the University of Hong Kong, Research Grant Council (17121714, HKU780613M, and HKU763312M); Collaborative Research Funds (C705514G) of Hong Kong; National Basic Research Program of China (973 Program 2015CB553603).

\section{Supporting information}

Additional Supporting Information may be found online in the supporting information tab for this article.

Figure S1. Polyclonal antibodies against wild type human lipocalin-2 or C87A selectively recognize different species of lipocalin-2. Equal amount of purified wild type human lipocalin-2 and C87A mutant were mixed in one test tube and then incubated with $2 \mu \mathrm{g}$ anti-human lipocalin-2 or anti-C87A antibody for 6 hours at $4^{\circ} \mathrm{C}$. Subsequently, $70 \mu \mathrm{L}$ of protein $\mathrm{A}$ sepharose bead slurry was added for immunoprecipitation. The precipitated proteins were separated in 15\% SDS-PAGE and detected with anti-pLcn2 antibody.

Figure S2. Detection of polyaminated and non-polyaminated lipocalin-2 in human urine samples. A, The concentrated urine samples were separated by SDS-PAGE (15 $\mu \mathrm{L} /$ lane) and then subjected to Western blotting detection by polyclonal antibodies against pLcn2 (anti-pLcn2) or npLcn2 (anti-npLcn2). B, Immunoprecipitation (ip) was performed in two of the nine urine samples using anti-pLcn2 and anti-npLcn2, respectively.
Polyamines attached to the precipitated lipocalin-2 protein were detected using antibodies recognizing spermidine.

Figure S3. Frequency distribution of serum (top) and urine (bottom) lipocalin-2 concentrations for samples of the Hong Kong healthy volunteer cohort. The $95^{\text {th }}$ and $75^{\text {th }}$ percentile values are indicated for both pLcn2 (left) and npLcn2 (right) levels.

Figure S4. Representative images of tissue sections stained by polyclonal antibodies against pLcn2 (left) or npLcn2 (right). The parietal pericardium tissue biopsies were collected from Danish patients during cardiothoracic surgery and subsequently processed for immunohistological analyses. Arrows indicate the different types of cells with pLcn2 or npLcn2 positive staining (brown color). A=Adipocytes, $M=$ Mesothelial cells, L=Leukocytes.

Figure S5. Comparison of cardiometabolic parameters among the three groups of samples. Based on the number of positively stained cells and the distribution pattern of npLcn2 (Figure 3), samples from Danish patient cohort were separated into three groups for comparison of their HDL, LDL, $\mathrm{HbAlc}$ and plasma adiponectin levels. ( $n=9-12$ ).

Figure S6. Neutrophil uptake of lipocalin-2 protein. A, Protein expression of human lipocalin-2 (arrow head) was detected by Western blotting in the cell lysates (10 $\mu \mathrm{g}$ total protein) collected from Met-5A cultures. Purified pLcn2 protein $(2 \mu \mathrm{g} /$ lane) was loaded at the left for comparison. B, Neutrophils isolated from mice without lipocalin-2 were incubated with the control (top) or conditioned (bottom) media collected from human primary mesothelial cell cultures. Immunofluorescence was performed to detect the protein content of human lipocalin-2 (red) inside the neutrophils. Nuclei were counterstained by DAPI (blue). Magnification, 400x. C, Genotyping was performed using the three sets of primers to identify Lcn2-floxed and Lys-LKO mice. Mice with a positive product of Primer 1 and 2 were selected as Lys-LKO mice. The control Lys-floxed mice had only the positive band of $319 \mathrm{bp}$ amplified by Primer 2. D, Neutrophils isolated from Lcn2-floxed and Lys-KO mice were subjected to quantitative PCR analysis to detect mRNA expression of lipocalin-2 (top) or Western blotting (bottom) to detect the presence of lipocalin-2 protein.

\section{References}

1. Flower DR. The lipocalin protein family: structure and function. Biochem $J$ 1996; 318(Pt 1): 1-14.

2. Kjeldsen L, Johnsen AH, Sengelov H, Borregaard N. Isolation and primary structure of NGAL, a novel protein associated with human neutrophil gelatinase. $J$ Biol Chem 1993; 268: 10425-10432.

3. Flo TH, Smith KD, Sato S, Rodriguez DJ, Holmes MA, Strong RK, Akira S, Aderem
A. Lipocalin 2 mediates an innate immune response to bacterial infection by sequestrating iron. Nature 2004; 432: 917-921.

4. Liu JT, Song E, Xu A, Berger T, Mak TW, Tse HF, Law IK, Huang B, Liang Y, Vanhoutte PM, Wang Y. Lipocalin-2 deficiency prevents endothelial dysfunction associated with dietary obesity: role of cytochrome P450 2C inhibition. $\mathrm{Br} J$ Pharmacol 2012; 165: 520-531.
5. Wang Y. Small lipid-binding proteins in regulating endothelial and vascular functions: focusing on adipocyte fatty acid binding protein and lipocalin-2. $B r \quad J$ Pharmacol 2012; 165: 603-621.

6. Yndestad A, Landro L, Ueland T, Dahl CP, Flo TH, Vinge LE, Espevik T, Froland SS, Husberg C, Christensen G, Dickstein K, Kjekshus J, Oie E, Gullestad L, Aukrust P. Increased systemic and 
myocardial expression of neutrophi gelatinase-associated lipocalin in clinical and experimental heart failure. Eur Heart $J$ 2009; 30: 1229-1236.

7. Viau A, El Karoui K, Laouari D, Burtin M, Nguyen C, Mori K, Pillebout E, Berger T, Mak TW, Knebelmann B, Friedlander G, Barasch J, Terzi F. Lipocalin 2 is essential for chronic kidney disease progression in mice and humans. J Clin Invest 2010; 120: 4065-4076.

8. Tarjus A, Martinez-Martinez E, Amador C, Latouche C, El Moghrabi S, Berger T, Mak TW, Fay R, Farman N, Rossignol P, Zannad F, Lopez-Andres N, Jaisser F. Neutrophil gelatinase-associated lipocalin, a novel mineralocorticoid biotarget, mediates vascular profibrotic effects of mineralocorticoids. Hypertension 2015; 66: 158-166.

9. Song E, Fan P, Huang B, Deng HB, Cheung BM, Feletou M, Vilaine JP, Villeneuve $\mathrm{N}$, Xu A, Vanhoutte PM, Wang Y. Deamidated lipocalin-2 induces endothelial dysfunction and hypertension in dietary obese mice. $J$ Am Heart Assoc 2014; 3: e000837.

10. Law IK, Xu A, Lam KS, Berger T, Mak TW, Vanhoutte PM, Liu JT, Sweeney G, Zhou M, Yang B, Wang Y. Lipocalin-2 deficiency attenuates insulin resistance associated with aging and obesity. Diabetes 2010; 59: 872-882.

11. Wang Y, Lam KS, Kraegen EW, Sweeney G, Zhang J, Tso AW, Chow WS, Wat NM, $\mathrm{Xu} J Y$, Hoo RL, Xu A. Lipocalin-2 is an inflammatory marker closely associated with obesity, insulin resistance, and hyperglycemia in humans. Clin Chem 2007; 53: 34-41.

12. Yan QW, Yang Q, Mody N, Graham TE, Hsu $\mathrm{CH}, \mathrm{Xu} \mathrm{Z}$, Houstis NE, Kahn BB, Rosen ED. The adipokine lipocalin 2 is regulated by obesity and promotes insulin resistance. Diabetes 2007; 56: 2533-2540.

13. James PT, Leach R, Kalamara E, Shayeghi M. The worldwide obesity epidemic. Obes Res 2001; 9(Suppl 4): 228S-233S.

14. Elie AG, Jensen PS, Nissen KD, Geraets $\mathrm{IM}$, Xu A, Song E, Hansen ML, Irmukhamedov A, Rasmussen LM, Wang Y, De Mey JG. Adipokine imbalance in the pericardial cavity of cardiac and vascular disease patients. PLoS One 2016; 11: e0154693.

15. Milner KL, van der Poorten $\mathrm{D}, \mathrm{Xu} \mathrm{A}$, Bugianesi E, Kench JG, Lam KS, Chisholm DJ, George J. Adipocyte fatty acid binding protein levels relate to inflammation and fibrosis in nonalcoholic fatty liver disease. Hepatology 2009; 49: 1926-1934.

16. Zhou M, Bao Y, Lu J, Zhou J, Jia W. Serum A-FABP is increased and closely associated with elevated NT-proBNP levels in type 2 diabetic patients treated with rosiglitazone. PLoS One 2011; 6 : e27032.

17. Xiao Y, Xu A, Law LS, Chen C, Li H, Li X, Yang L, Liu S, Zhou Z, Lam KS. Distinct changes in serum fibroblast growth factor 21 levels in different subtypes of diabetes. J Clin Endocrinol Metab 2012; 97: E54-E58.

18. Lin Z, Tian H, Lam KS, Lin S, Hoo RC, Konishi M, Itoh N, Wang Y, Bornstein $\mathrm{SR}, \mathrm{Xu} \mathrm{A}$, Li X. Adiponectin mediates the metabolic effects of FGF21 on glucose homeostasis and insulin sensitivity in mice. Cell Metab 2013; 17: 779-789.

19. Xiao Y, Xu A, Hui X, Zhou P, Li X, Zhong $\mathrm{H}$, Tang W, Huang G, Zhou Z. Circulating lipocalin-2 and retinolbinding protein 4 are associated with intima-media thickness and subclinical atherosclerosis in patients with type 2 diabetes. PLoS One 2013; 8: e66607.

20. Yu H, Xia F, Lam KS, Wang Y, Bao Y, Zhang J, Gu Y, Zhou P, Lu J, Jia W, $\mathrm{Xu} \mathrm{A}$. Circadian rhythm of circulating fibroblast growth factor 21 is related to diurnal changes in fatty acids in humans. Clin Chem 2011; 57: 691-700.

21. Xu A, Chan KW, Hoo RL, Wang Y, Tan KC, Zhang J, Chen B, Lam MC, Tse C, Cooper GJ, Lam KS. Testosterone selectively reduces the high molecular weight form of adiponectin by inhibiting its secretion from adipocytes. $J$ Biol Chem 2005; 280: 18073-18080.

22. Xu A, Wang Y, Xu JY, Stejskal D, Tam S, Zhang J, Wat NM, Wong WK, Lam KS. Adipocyte fatty acid-binding protein is a plasma biomarker closely associated with obesity and metabolic syndrome. Clin Chem 2006; 52: 405-413.

23. Third Report of the National Cholesterol Education Program (NCEP) Expert Panel on Detection, Evaluation, and Treatment of High Blood Cholesterol in Adults (Adult Treatment Panel III) final report. Circulation 2002; 106: 3143-3421.

24. Bonventre JV. Kidney injury molecule-1: a translational journey. Trans Am Clin Climatol Assoc 2014; 125: 293-299.

25. Chakraborty S, Kaur S, Guha S, Batra SK. The multifaceted roles of neutrophil gelatinase associated lipocalin (NGAL) in inflammation and cancer. Biochim Biophys Acta 2012; 1826: 129-169.

26. Mori K, Lee HT, Rapoport D, Drexler IR, Foster K, Yang J, Schmidt-Ott KM, Chen X, Li JY, Weiss S, Mishra J, Cheema FH, Markowitz G, Suganami T, Sawai K, Mukoyama M, Kunis C, D'Agati V, Devarajan P, Barasch J. Endocytic delivery of lipocalin-siderophore-iron complex rescues the kidney from ischemiareperfusion injury. $J$ Clin Invest 2005; 115: 610-621.

27. Donadio C. Effect of glomerular filtration rate impairment on diagnostic performance of neutrophil gelatinaseassociated lipocalin and B-type natriuretic peptide as markers of acute cardiac and renal failure in chronic kidney disease patients. Crit Care 2014; 18: R39.

28. Clerico A, Galli C, Fortunato A, Ronco C. Neutrophil gelatinase-associated lipocalin (NGAL) as biomarker of acute kidney injury: a review of the laboratory characteristics and clinical evidences. Clin Chem Lab Med 2012; 50: 1505-1517.

29. Cullen MR, Murray PT, Fitzgibbon MC. Establishment of a reference interval for urinary neutrophil gelatinaseassociated lipocalin. Ann Clin Biochem 2012; 49(Pt 2): 190-193.

30. Le Cabec V, Calafat J, Borregaard N. Sorting of the specific granule protein, NGAL, during granulocytic maturation of HL-60 cells. Blood 1997; 89: 2113-2121.

31. Hochmeister S, Engel O, Adzemovic MZ, Pekar T, Kendlbacher P, Zeitelhofer M, Haindl M, Meisel A, Fazekas F, SeifertHeld T. Lipocalin-2 as an infectionrelated biomarker to predict clinical outcome in ischemic stroke. PLoS One 2016; 11: e0154797.

32. Waikar SS, Bonventre JV. Biomarkers for the diagnosis of acute kidney injury. Nephron Clin Pract 2008; 109: c192-c197.

33. Pawluczyk IZ, Furness PN, Harris KP. Macrophage-induced rat mesangial cell expression of the 24p3-like protein alpha-2-microglobulin-related protein. Biochim Biophys Acta 2003; 1645 : 218-227.

34. Dieterle F, Perentes E, Cordier A, Roth DR, Verdes P, Grenet O, Pantano S, Moulin P, Wahl D, Mahl A, End P, Staedtler F, Legay F, Carl K, Laurie D, Chibout SD, Vonderscher J, Maurer G. Urinary clusterin, cystatin $\mathrm{C}$, beta2-microglobulin and total protein as markers to detect drug-induced kidney injury. Nat Biotechnol 2010; 28: 463-469.

35. Schmidt-Ott KM, Mori K, Kalandadze A, Li JY, Paragas N, Nicholas $\mathrm{T}$, Devarajan P, Barasch J. Neutrophil gelatinase-associated lipocalinmediated iron traffic in kidney epithelia. Curr Opin Nephrol Hypertens 2006; 15: 442-449.

36. Damman K, van Veldhuisen DJ, Navis G, Voors AA, Hillege HL. Urinary neutrophil gelatinase associated lipocalin (NGAL), a marker of tubular damage, is increased in patients with chronic heart failure. Eur $J$ Heart Fail 2008; 10: 997-1000.

37. Bolignano D, Coppolino G, Lacquaniti A, Buemi M. From kidney to cardiovascular diseases: NGAL as a biomarker beyond the confines of nephrology. Eur J Clin Invest 2010; 40: 273-276.

38. Iqbal N, Alim KS, Aramin H, Iqbal F, Green E, Higginbotham E, Maisel AS. Novel biomarkers for heart failure. Expert Rev Cardiovasc Ther 2013; 11: 1155-1169.

39. van Deursen VM, Damman K, Voors AA van der Wal $\mathrm{MH}$, Jaarsma $\mathrm{T}$, van Veldhuisen DJ, Hillege HL. Prognostic value of plasma neutrophil gelatinase-associated lipocalin for mortality in patients with heart failure. Circ Heart Fail 2014; 7: 35-42. 
40. Minana G, Rumiz E, Palau P, Valero E, Bodi V, Nunez E, Sanchis J, Nunez J. Plasma neutrophil gelatinase-associated lipocalin and long-term mortality in patients with acute heart failure and normal renal function. Int $J$ Cardiol 2016; 214: 51-53.

41. Alvelos M, Lourenco P, Dias C, Amorim M, Rema J, Leite AB, Guimaraes JT, Almeida P, Bettencourt P. Prognostic value of neutrophil gelatinase-associated lipocalin in acute heart failure. Int $J$ Cardiol 2013; 165: 51-55.

42. Wagener G, Jan M, Kim M, Mori K, Barasch JM, Sladen RN, Lee HT. Association between increases in urinary neutrophil gelatinase-associated lipocalin and acute renal dysfunction after adult cardiac surgery. Anesthesiology 2006; 105: 485-491.

43. Palazzuoli A, Ruocco G, Beltrami M, Franci B, Pellegrini M, Lucani B, Nuti $\mathrm{R}$, Ronco C. Admission plasma neutrophil gelatinase associated lipocalin (NGAL) predicts worsening renal function during hospitalization and post discharge outcome in patients with acute heart failure. Acute Card Care 2014; 16: 93-101.

44. Mori K, Nakao K. Neutrophil gelatinaseassociated lipocalin as the real-time indicator of active kidney damage. Kidney Int 2007; 71: 967-970.

45. Haase M, Bellomo R, Devarajan P, Schlattmann P, Haase-Fielitz A. Accuracy of neutrophil gelatinaseassociated lipocalin (NGAL) in diagnosis and prognosis in acute kidney injury: a systematic review and meta-analysis. Am J Kidney Dis 2009; 54: 1012-1024.

46. Alvelos M, Pimentel R, Pinho E, Gomes A, Lourenco P, Teles MJ, Almeida P, Guimaraes JT, Bettencourt P. Neutrophil gelatinase-associated lipocalin in the diagnosis of type 1 cardio-renal syndrome in the general ward. Clin $J$ Am Soc Nephrol 2011; 6: 476-481.

47. Poniatowski B, Malyszko J, Bachorzewska-Gajewska H, Malyszko JS, Dobrzycki S. Serum neutrophil gelatinase-associated lipocalin as a marker of renal function in patients with chronic heart failure and coronary artery disease. Kidney Blood Press Res 2009; 32: 77-80.

48. Katagiri M, Takahashi M, Doi K, Myojo M, Kiyosue A, Ando J, Hirata Y, Komuro I. Serum neutrophil gelatinaseassociated lipocalin concentration reflects severity of coronary artery disease in patients without heart failure and chronic kidney disease. Heart Vessels 2016; 31: 1595-1602.

49. Mutsaers SE, Birnie K, Lansley S, Herrick SE, Lim CB, Prele CM. Mesothelial cells in tissue repair and fibrosis. Front Pharmacol 2015; 6: 113. 